Florida International University FIU Digital Commons

FIU Electronic Theses and Dissertations

University Graduate School

7-15-2005

\title{
Perceived energy expenditure for physical activity in male and female adults
}

Su-Nui Escobar

Florida International University

DOI: $10.25148 /$ etd.FI15101309

Follow this and additional works at: https://digitalcommons.fiu.edu/etd

Part of the Dietetics and Clinical Nutrition Commons

\section{Recommended Citation}

Escobar, Su-Nui, "Perceived energy expenditure for physical activity in male and female adults" (2005). FIU Electronic Theses and Dissertations. 3151.

https://digitalcommons.fiu.edu/etd/3151

This work is brought to you for free and open access by the University Graduate School at FIU Digital Commons. It has been accepted for inclusion in FIU Electronic Theses and Dissertations by an authorized administrator of FIU Digital Commons. For more information, please contact dcc@fiu.edu. 


\section{FLORIDA INTERNATIONAL UNIVERSITY}

Miami, Florida

PERCEIVED ENERGY EXPENDITURE FOR PHYSICAL ACTIVITY IN MALE AND FEMALE ADULTS

A thesis submitted in partial fulfillment of the

requirements for the degree of

MASTER OF SCIENCE

in

DIETETICS AND NUTRITION

by

Su-Nui Escobar

2005 
To: Dean Ronald M. Berkman

College of Health and Urban Affairs

This thesis, written by Su-Nui Escobar, and entitled Perceived Energy Expenditure for Physical Activity in Male and Female Adults, having been approved in respect to style and intellectual content, is referred to you for judgment.

We have read this thesis and recommend that it be approved.

Michele Ciccazzo

Victoria Hammer Castellanos

Valerie George, Major Professor

Date of Defense: July 15, 2004

The thesis of Su-Nui Escobar is approved.

Dean Ronald M. Berkman

College of Health and Urban Affairs

Dean Douglas Wartzok University Graduate School

Florida International University, 2005 


\section{DEDICATION}

I would like to dedicate this thesis to my parents, who encouraged me to follow my dreams. Without their love and support, the completion of this work would not have been possible. To my sister, Nadia, whose own commitment and enthusiasm for life and her profession are an example to follow. Also, to all my friends whose words of encouragement supported me day by day. 


\section{ACKNOWLEDGMENTS}

I wish to thank the members of my committee, Dr. Michele Ciccazzo and Dr.Victoria Castellanos. Their guidance through this process was invaluable- thank you for your patience and advice. My most sincere gratitude to Paulette Johnson for all of the help she gave with my statistics. Finally, I would like to thank my major professor, Dr. Valerie George, who has taught me a great deal about the research process and will be, always, a role model to follow. Her words of encouragement and her patience made my work possible. 
ABSTRACT OF THE THESIS

PERCEIVED ENERGY EXPENDITURE FOR PHYSICAL ACTIVITY IN MALE

AND FEMALE ADULTS

by

Su-Nui Escobar

Florida International University, 2005

Miami, Florida

Professor Valerie George, Major Professor

The purpose of this study was to gain further insight into the relationship between perceived energy expenditure (EE) for physical activity (PA) and age, gender, Body Mass Index (BMI), education, and leisure time PA (LTPA) levels. A 19-item interviewer administered questionnaire was completed by 798 individuals to assess accuracy of perception of EE (in calories) for various types of PA (sedentary, moderate and vigorous). Participants, age 21 to 64 years, were recruited from ten sites of the Department of Motor Vehicles in Miami, Florida. Only $30 \%$ were able to accurately assess EE for PA. Higher education and age were associated with greater accuracy. The range for estimated EE for PA was from 0-60,000 calories. These results are of interest as they suggest efforts should be made to educate the public regarding EE for PA in reference to energy balance and weight management. 


\section{TABLE OF CONTENTS}

CHAPTER

PAGE

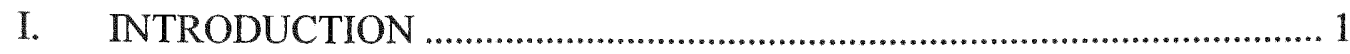

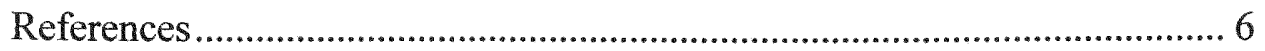

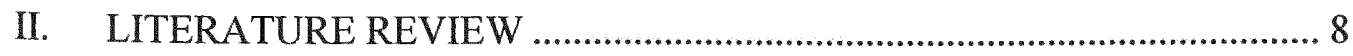

Overweight and obesity trends by age, gender, socioeconomic status, and ethnic/race groups ............................................. 8

The role of energy intake and energy expenditure in the etiology of obesity........................................................................ 10

Patterns and trends in physical activity in U.S. adults ............................... 11

Factors influencing energy intake and energy expenditure .......................... 14

A review of theories about knowledge and health behavior .......................... 20

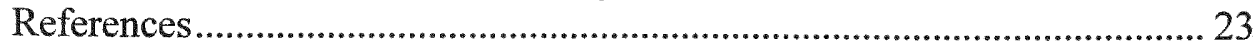

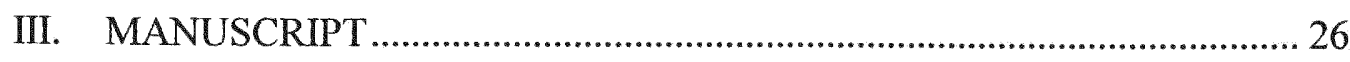

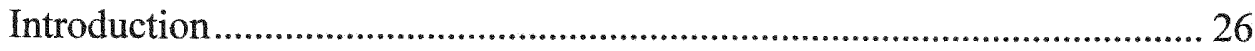

Research methods and procedures ……................................................ 28

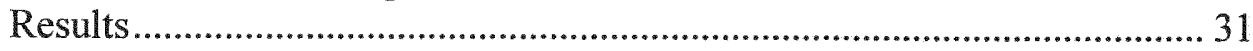

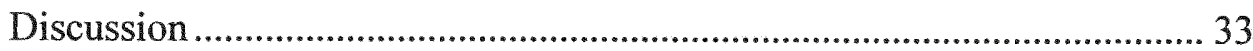

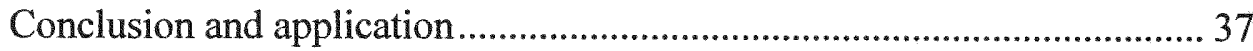

References................................................................................. 42

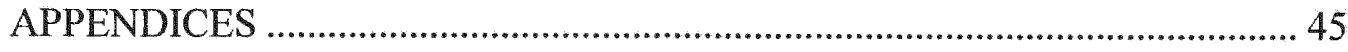




\section{CHAPTER I}

\section{INTRODUCTION AND RESEARCH QUESTIONS}

Overweight and obesity have reached epidemic proportions in the United States. Recently it has been reported that $64.5 \%$ of U.S. adults are overweight or obese (1). This is a dramatic increase when compared with $1976-1980$ estimates in which $32 \%$ of adults were reported overweight and $15 \%$ obese (2). This increase in overweight and obesity is particularly evident in minority populations. Data from the latest National Health and Nutrition Examination Survey (NHANES 1999-2000) (1) shows that Hispanic males have a higher prevalence of obesity (29\%) than non-Hispanic blacks (28\%) or nonHispanic whites (27\%). In females, non-Hispanic black women (50\%) and MexicanAmerican women (40\%) have a greater instance of obesity than non-Hispanic white women $(30 \%)$.

Overweight and obesity have become one of the most pressing health problems in the United States (3). Inadequate diet and physical inactivity account for approximately 400,000 deaths per year (4). It has been well established that excess body weight is an important risk factor for type 2 diabetes, hypertension, stroke, heart disease, gallbladder disease, sleep apnea, certain cancers (i.e., endometrial, breast, prostate, and colon), ostereo-arthritis, dislipidemia and reproductive complications as well as certain psychological disorders (depression, eating disorders, distorted body image, and low selfesteem) (5-9). According to the World Health Organization, overweight is defined as a body mass index $(\mathrm{BMI}) \geq 25$, obesity as a $\mathrm{BMI} \geq 30$, and extreme obesity a $\mathrm{BMI} \geq 40$ (10). In the year 2000, it was estimated that direct and indirect costs associated with 
overweight and obesity amounted to approximately $\$ 117,000$ billion dollars (3). It has been reported that health care costs increase $36 \%$ for individuals with a BMI $\geq 30$ and $20 \%$ for those with a BMI of $\geq 25(11)$.

Overweight and obesity are the result of the positive energy balance in relation to energy intake (EI) and energy expenditure (EE), over an extended period of time $(6,12)$. Energy Intake is defined as the consumption of food and caloric fluid, which can be described quantitatively (intake of calories) and qualitatively (macronutrient intake). Energy expenditure has three primary components: a) basal metabolic rate, BMR (65$70 \%$ of total expenditure), b) thermic effect of food ( $10 \%$ of daily EE), and c) energy expend for physical activity (20-25\% of total EE) (12-13). If an individual desires to lose weight, they can either reduce their EI or increase their EE by being more physically active (13).

Psychological, biological and cognitive factors contribute to the EI and EE of an individual (12). Lifestyle behaviors that influence diet and participation in physical activity (PA) may be influenced by cognition, i.e., knowledge, beliefs, and understanding about $\mathrm{EI}$ and $\mathrm{EE}$. Some individuals use information regarding calories in $\mathrm{EI}$ and $\mathrm{EE}$ to create a plan to manage their weight. It has been reported that eating fewer calories is one of the most commonly used strategies for weight loss (14). Other studies have found that some individuals use calorie information to select food items (15-16). Therefore, accuracy in perception of calories in food might play an important role in the EI of some individuals.

Other studies suggest that knowledge, along with other factors, might have an important impact on EI (17-20). For example, Wardle et al (17) found that nutrition 
knowledge explained 4 to $22 \%$ of the variation in intake of fruits, vegetables and fat among 1,046 adults randomly selected from General Practitioners' lists in England. A study by Neuhoser (18) explored the use of knowledge provided by nutrition labels in the adoption of dietary behaviors. Researchers reported that the use of nutrition labels had a significant association with a diet lower in fat. Furthermore, nutrition knowledge, after controlling for demographics, psychosocial, and behavioral variables, accounted for $6 \%$ of the variation in fat intake.

Recently, the United States Department of Health and Human Services (HHS) unveiled a Food and Drug Administration strategy to aid in the campaign to reduce overweight and obesity (21). The focus is a "calories count" approach. Recommendations are centered on the importance of educating consumers on the fact that weight control is primarily a function of calorie balance. The FDA recommendations include: revisions of food labels to highlight the role calories play in the maintenance of an adequate diet, authorizations of health claims on foods that meet the definition of "low or reduced calories", displays of nutrition information for consumers at restaurant establishments, and dietary guidance statements by manufactures to educate consumers about the importance of a balanced EI and EE.

It is possible that cognition influences participation in PA and ultimately EE. For example, if individuals believe they have expended many calories performing a specific PA, they may think that they do not need to do any other PA during the rest of the day or they may believe that they should increase their EI. In a study by Woo et al. (22), designed to determine the effect of increased PA on EI and energy balance in obese females, researchers found that participants decreased their usual PA during the rest of 
the day after completing an assigned exercise. In a recent study, Visona and George (23) reported that participants were unable to accurately estimate EE in reference to 60 minutes of moderate intensity walking on a treadmill and 60 minutes at rest. Accuracy varied from approximately $20 \%$ to $60 \%$. These variations in estimated EE were related to dieting status. In addition, the researchers found that participants were unable to accurately assess caloric content of their lunch meal after moderate exercise (participants overestimated content by as much as $40 \%$ ).

Very little information is available in the literature regarding the perception of caloric expenditure for different PA. Information on perceived calories expended during PA of daily life will provide insight into the relationship between cognition and PA, ultimately leading to an understanding of how perceived EE for PA could influence body weight.

\section{$\underline{\text { Research question }}$}

Are there differences between groups of people in reference to BMI, gender, age, education, and LTPA levels in their ability to accurately estimate EE for daily PA?

\section{Hypotheses}

1. There are significant differences between males and females in their perception of EE for different PA.

2. Overweight and obese individuals have a less accurate perception of the number of calories expended for different PA than normal weight individuals.

3. Individuals with higher leisure time PA (LTPA) levels are more accurate in their perception of the number of calories expended for PA than those with lower levels for LTPA. 
4. Age groups differ in their perception of number of calories expanded for PA, with younger adults being more accurate than older adults.

5. Individuals with a higher level of education are more accurate in their perception of the number of calories expended for PA than those with a lower level of education. 


\section{REFERENCES}

1. Flegal KM, Carroll MD, Kuczmarski RJ, Johnson CL. Prevalence and trends in obesity among US adults, 1999-2000. J Am Med Assoc. 2002;88:1723-1727.

2. Eberhardt MS and Makuc DM. Health, United States, 2001: Urban and rural health chartbook. National Center for Health Statistics. Available at http://www.cdc.gov/nchs/data/hus/hus01.pdf. Acessed August 23, 2004.

3. U.S. Department of Health and Human Services. The Surgeon General's call to action to prevent and decrease and obesity. Available from:

http://www.surgeongeneral.gov/topics/obesity/calltoaction/CalltoAction.pdf. Assessed July 18, 2004.

4. Mokdad AH, Marks JS, Stroup DF, Gerberding JL. Actual causes of death in United States, 2000. J Am Med Assoc. 2004;291:1238-1245.

5. Pi-Sunyer FX. Medical hazards of obesity. Ann Intern Med. 1993;119:655-660.

6. Lyznicki J, Young D, Riggs J, Davis R. Obesity: Assessment and management in primary care. Am Fam Physician. 2001;63:2185-2196.

7. Hu FB, Manson J, Stampfer MJ, Colditz G, Liu S, Solomon CG, Willett WC. Diet, lifestyle, and the risk of type-2 diabetes mellitus in women. $N$ Engl J Med. 2001;345:790-797.

8. Sampfer MJ, Hu FB, Manson JE, Rimm EB, Willet WC. Primary prevention of coronary heart disease in women through diet and lifestyle. $N$ Engl $J$ Med. 2000;343:16-22.

9. Must A, Spadano J, Coakley EH, Field AE, Colditz G, Dietz WH. The burden associated with overweight and obesity. J Am Med Assoc. 1999;282:1523-1529.

10. WHO Consultation on Obesity. Obesity: Preventing and managing the global epidemic. Geneva, Switzerland: World Health Organization. WHO Technical Report Series. 2000;894.

11. Thompson D, Brown JB, Nichols GA, Elmer PJ, Oster G. Body mass index and future healthcare costs: A retrospective cohort study. Obes Res. 2001;9:210-218.

12. Goran MI, Treuth MS. Energy expenditure, physical activity, and obesity in children. Pediatr Clin North Am. 2001;48:931-953.

13. Groff JL, Gropper SS. Advanced Nutrition and Human Metabolism. $3^{\text {rd }}$ ed. Wadsworth: Thomson Learning. Belmont, CA. 1999. 
14. Kruger J, Galuska DA, Serdula MK, Jones DA. Attempting to lose weight. Specific practices among U.S. adults. Am J Prev Med. 2004;26: 402-406.

15. Mangweth B, Hudson JI, Pope HG, Oberleit S, De Col C, Kinzl J. Knowledge of calories and its effect on eating behavior in overweight, normal weight, and underweight individuals. Eat Weight Disord. 1999;4:165-168.

16. Brewer JL, Blake AJ, Rankin SA, Douglas LW. Theory of reasoned action predicts milk consumption in women. $J$ Am Meds Assoc. 1999;99:39-44.

17. Wardle K, Parmenter K, Waller J. Nutrition knowledge and food intake, Appetite. $2000 ; 34 ; 269-275$.

18. Neuhouser ML, Kristal AR, Patterson RE. Use of food nutrition labels is associated with lower fat intake. J Am Med Assoc. 1999;99:45-50,53.

19. Larsson I, Lissner L, Wilhelmsen L. The "Green Keyhole': nutritional knowledge may influence food selection. Eur J Clin Nutr. 1999;53:776-780.

20. Miller DL, Castellanos VH, Shide DJ, Peters JC, Rolls BJ. Effect of fat-free potato chips with and without nutrition labels on fat and energy intakes. Am J Clin Nutr. 1998;8:282-290.

21. FDA Obesity Workgroup. HHS Tackles Obesity. FDA Consumers Magazine. Available at: http://www.fda.goc/fdac/features/2004/304. Accessed June 6, 2004.

22. Woo R, Garrow JS, Pi-Sunyer FX. Effects on spontaneous calorie intake in obesity. Am J of Clin Nutr. 1982;36:470-477.

23. Visona C, George VA. The impact of dieting status and restraint on post-exercise energy intake in overweight females. Obes Res. 2002;10:1251-1258. 


\section{CHAPTER II}

\section{LITERATURE REVIEW}

This literature review presents information on the prevalence of overweight, obesity and physical activity (PA) in the United States. It also explores the role that cognitive factors (i.e., knowledge, beliefs, and understanding about energy intake and energy expenditure) may play in energy balance and, ultimately, in weight management.

\section{Overweight and obesity trends by age, gender, socioeconomic status and race/ethnic}

\section{groups among US adults}

The prevalence of overweight and obesity continues to increase in the United States across all age, racial/ethnic and socioeconomic (SES) groups as well as in both genders. However, there are some disparities among different groups of the population in regards to the prevalence of overweight and obesity (1-2). Overweight is defined as a $\mathrm{BMI} \geq 25$, obesity as a BMI $\geq 30$, and extreme obesity a BMI $\geq 40$. These definitions are consistent with those of the World Health Organization (3).

In both genders, the prevalence of overweight and obesity increases with advancing age and declines after the age of 80 . When looking at the prevalence of obesity alone, significant increases occurred between the NHANES III (1988-1994) and NHANES 1999-2000 in all age groups, except for men aged 40-59 years, for which the increase was not statistically significant (2). 
Among females, the prevalence of overweight and obesity is higher among members of racial and ethnic minorities than among non-Hispanic whites. Data from the most recent NHANES shows that, in women, the prevalence of obesity is higher among non-Hispanic Blacks (50\%) followed by Mexican-Americans (40\%) and non-Hispanic whites (30\%). Among males, it has been reported that Hispanics have a higher prevalence of obesity (29\%) than non-Hispanic Blacks (28\%) or non-Hispanic whites (27\%) (2). Within some minority groups, rates of overweight and obesity differ between genders. For example, $69 \%$ of non-Hispanic black women are either overweight or obese compared with $58 \%$ of males. Sixty two percent of non-Hispanic men are overweight compared to $47 \%$ of women. However, when looking at obesity alone, more nonHispanic white women are categorized as obese compared to men (23\% to $21 \%)(1)$. SES also plays a part in the prevalence of overweight and obesity. Across all racial and ethnic groups, women of lower SES $(\leq 130 \%$ of the poverty threshold) are more likely to be obese than those with a higher SES (1).

\section{Summary}

The high prevalence of overweight and obesity occurs in all age, gender, SES, and racial/ethnic groups. It is particularly evident among older adults and minority groups. Among women, non-Hispanic black women reported the highest prevalence of obesity, followed by Hispanics, and non-Hispanic whites. Among men, the differences are slight; Hispanics have the highest prevalence, followed by non-Hispanic blacks and nonHispanic whites. Finally, across all racial and ethnic groups, women in the lower SES have the highest prevalence of overweight and obesity. 


\section{The role of energy intake (E) and energy expenditure (EE) in the etiology of obesity}

Overweight and obesity are the result of the positive energy balance in relation to $\mathrm{EI}$ and $\mathrm{EE}$, over an extended period of time (4-5). Energy intake is the caloric (energy) content of food as provided by the primary macronutrients: carbohydrates, protein, fat and alcohol (5). The body uses energy from these macronutrients to perform cellular, metabolic and mechanical work (EE). Most energy (65-70\%) is used to maintain body functions (i.e., heart beat, involuntary muscle contraction and function, and respiration). In addition to this, the body expends energy to digest, metabolize and store food. This is called thermic effect of food (TEF). Typically, TEF constitutes about $10 \%$ of caloric intake. Physical activity accounts for $20-25 \%$ of total EE (5-6) and includes exercise and activities of daily living. Physical activity is the only component of EE that is easily modifiable.

\section{Physical activity}

Physical activity encompasses all types of activity, including sports and leisure activities, occupationally related activities, and activities of daily living (7). The energy expended by activity is determined by various factors including, duration (i.e. time), type of activity (i.e. resting, walking, running), intensity, the BMI of the individual, and the efficiency at which the activity is performed.

The intensity of different PA is often categorized as light, moderate, or vigorous. Despite this, many activities can be classified in any one, or all three categories, depending upon the level of personal effort involved. For example, an individual can bicycle at intensities ranging from light to vigorous. One method of measuring PA at 
different levels of effort is based on the "metabolic equivalent level" (MET) (8). A MET is the ratio of energy expended in kilojoules or kilocalories divided by resting energy expenditure (REE) in kilojoules or kilocalories, which is measured or estimated based on body weight (9). By definition, 1 MET is equivalent to the energy used by the body when an individual sits quietly. The more intense the body works during a specific activity, the higher the number of METs. For example, an activity that expends 3-6 METs, is considered moderate-intensity PA, and an activity that expends $\geq 6$ METs is considered vigorous-intensity PA (8). The daily cumulative total EE for PA varies widely between individuals and accounts for the greatest source of differences in EE, consequently having an important impact on energy balance.

\section{Leisure time PA (LTPA)}

Advances in technology, especially in Western societies, have significantly decreased occupationally related PA. Therefore, LTPA has become the most commonly used method to assess PA levels. Today, LTPA plays the greatest role in the energy balance equation as the most modifiable component of EE (10).

\section{Patterns and trends in PA in U.S. adults}

The Surgeon General's Report suggests that men and women of all ages can benefit from a moderate amount of PA most days of the week. This can be achieved by 30 minutes of moderate intensity activities such as brisk walking, easy bicycling, dancing, or playing tennis; or 15-20 minutes of higher intensity PA such as running, high impact aerobics, playing basketball or swimming. Nevertheless, $60 \%$ of U.S. adults do not engage in the recommended amount of activity and $25 \%$ of the population is inactive (10). 


\section{Trends by gender, age, socioeconomic status and race/ethnic groups}

Similar to the prevalence of overweight and obesity, there appears to be differences in participation in PA by gender, age, ethnicity and SES groups. Recent data from the 2000 National Health Interview Survey (NHIS), conducted by the Centers for Disease Control and Prevention (CDC) and the National Center for Health Statistics (NCHS), reported that men (21\%) were more likely than women $(17 \%)$ to engage in a high level PA. However, both genders were equally likely to engage in moderate level PA (50\% men and $49 \%$ women). In addition, men ( $35 \%)$ were more likely than women (29\%) to engage in regular LTPA (11). Not surprisingly, women were more likely to be physically inactive than men (12\% compared to $7 \%)(10-11)$.

Participation in PA has been reported to be higher among young adults aged 1829 years. Overall, participation in PA declines with age (10). However, while weight lifting and vigorous, or contact sports, declined significantly with age, other activities such as walking, gardening and golf increased considerably with age (10).

According to data from both the CDC Surgeon General's Report on PA and Health, and the 2000 NHIS (10-11) there are differences in participation in PA by race and ethnicity. Non-Hispanic white adults reported engaging in higher levels of PA than other ethnic groups. However, the same group reported to be more likely to sit during their daily activities than Non-Hispanic Blacks or Hispanics. Physical inactivity was reported to be more common among minorities (African American and Hispanic adults). African American men (11\%) had the highest percentage of physical inactivity followed by Hispanic men ( $9 \%)$ and non-Hispanic white men ( $7 \%)$. Similar trends were reported 
among women. Non-Hispanic blacks (19\%) have the highest prevalence of physical inactivity when compared with Hispanics (14\%) and non-Hispanic whites (10\%).

Education and income level also play a role in participation in PA (10-11). For example, data from the NHIS 2000 indicated that $9 \%$ of adults with only high school degrees were physically inactive, compared with $7 \%$ of those with an advanced degree (11). In addition, the proportion of adults reporting regular, vigorous activity was higher with each increasing educational category. Adults who had college degrees reported regular, vigorous activity approximately two to three times more often than those who had not completed high school (10). However, adults with a bachelor's degree or an advanced degree were more likely to sit during their usual daily activities (11). Physical inactivity was reported to be greatest among individuals with low-income level. It has been reported that adults with income levels below the poverty line were three times more likely than adults whose income is four times or more above the poverty level to never be physically active (11).

Participation in specific physical activities by gender, age, socioeconomic status and race and ethnic groups

The most recent Surgeon General's Report on PA and Health (10) states that the most frequent PA reported by individuals includes walking, gardening, stretching exercises, bicycling, strengthening exercises, stair climbing, jogging or running, aerobics or aerobic dancing, and swimming. When assessed by gender, males more commonly reported yard work, strengthening exercises, jogging or running, and vigorous or contact sports. Females engaged more frequently in walking and aerobics. Equal participation 
occurred in stretching exercises, bicycling, stair climbing and swimming. Participation in most exercises, particularly weight lifting and vigorous or contact sports, declined significantly with age. The prevalence of walking, gardening and golf tended to remain stable or increase with age.

Summary

Sixty percent of U.S. adults do not engage regularly in the recommended amounts of PA. Similar to the prevalence of overweight and obesity, levels of participation in PA differ among various groups of the population. Physical inactivity is more common among women, non-Hispanic blacks, older adults, and those with lower levels of education and income level (10-11).

\section{Factors influencing EI and EE}

In an effort to understand the current trends of overweight and obesity, and the increasing prevalence of physical inactivity, it is important to consider the factors influencing both EI and EE. It has been suggested that psychological, biological and cognitive factors (knowledge, attitudes and beliefs) influence both EI and EE (5). This literature review focuses on the cognitive factors.

\section{Energy Intake}

Role of knowledge in overweight and obesity

It has been suggested that knowledge, attitude, and beliefs related to food and eating will influence eating behaviors (12-16). Furthermore, it has been shown that some 
individuals use knowledge of calories as a tool to manage or lose weight (17-18). The following studies explore the relationship between knowledge and EI.

Nutrition knowledge and EI

Although the relationship between knowledge and behavior is complex, several studies suggest that nutrition knowledge is an important component influencing EI (1214). A recent study among 1,040 adults randomly selected from General Practitioners' lists in England found that nutrition knowledge was associated with greater fruit and vegetable intake and lower fat intake (12). The data suggested that nutrition knowledge explained between 4 to $22 \%$ of the variation in EI.

Other studies have reported that nutrition knowledge might also influence food selection. For example, Larsson et al (13) investigated the knowledge of the Green Keyhole symbol, used in Sweden to denote low fat, high-fiber food options, and its correlation with the intake of such food items. This cross-sectional study included 732 males and 859 females, ages 25-64 years. Intakes of Green Keyhole labelled low-fat foods were significantly higher in males $(\mathrm{P}=0.0443)$ and females $(\mathrm{P}<0.0001)$ with knowledge of the symbol than without. In addition, the study found that participants with this knowledge were significantly younger and (among women) thinner. However, it is important to know that in certain sub-groups, particularly in the less educated, the knowledge of the symbol did not appear to be correlated with dietary practices.

A study by Neuhoser et al. (14) explored the use of knowledge provided by nutrition labels in the adoption of dietary behaviors. Researchers reported that the use of nutrition labels had a significant association with a diet lower in fat. The use of nutrition 
labels was higher among women (87\%), adults younger than 35 years of age (80\%), and those with more than a high school education (85\%). The study (after controlling for demographics, psychosocial, and behavioral variables) showed that nutrition knowledge explained $6 \%$ of the variance in fat intake.

Miller et al. (15) investigated the effects of fat-free potato chips (with and without nutrition labels) on fat intake and EI. Ninety-five healthy individuals, ages 18-40 years participated in the study. Participants were categorized according to gender and level of dietary restraint, which refers to the degree to which individuals restrain or restrict their food intake because of concern about body weight. Subjects went to the research site daily during two 2 -week periods. During the first period, they received the same type of potato chips (either regular or fat-free), followed by a 1-week wash out period. During the second period participants received the other type of potato chip. The study was conducted under two information conditions: 1) subjects were provided with nutrition information about the chips; 2) the nutrition information was not provided. In both conditions, participants ate potato chips ad libitum. Under the no information condition, participants ate more regular chips than fat-free potato chips. There was no difference between restrained and unrestrained individuals. Under the information condition, low restraint participants ate similar amounts of fat-free and regular chips while high restraint participants ate significantly more fat-free chips. The researchers concluded that knowledge of the fat content of potato chips impacted EI for individuals with a high dietary restraint. 
Knowledge of calories and EI

A few studies have reported that some individuals use the information about calories in food to manage their weight (16-18). Mangweth et al. (18) assessed the changes in the eating behavior of the overweight, normal weight and underweight individuals $(\mathrm{n}=1,041)$ in response to knowledge about the caloric content of their food. The study was conducted at a university hospital cafeteria shortly after it began displaying the caloric content of all the meals. Researchers found that overweight individuals more frequently changed their eating behavior and food choices in response to the information on the caloric content of the food.

In a study by Brewer et al. (16), a larger proportion of participants $(n=100)$ reported drinking more skim milk than $1 \%, 2 \%$ and whole milk, despite evidence showing that skim milk had significantly lower scores for taste and texture than the other types of milk. On the other hand, participants also reported their beliefs that skim milk was better for them and was lower in calories than the $1 \%, 2 \%$ and whole milk.

Eating fewer calories has been reported to be the most commonly used strategy for weight loss (17). This study used information based on data from the 1998 National Health Interview Survey (NHIS), which was conducted among a representative sample of U.S. adults $(n=32,440)$. The results indicated that $24 \%$ of men and $37 \%$ of women were trying to lose weight. Such behavior increased as BMI and age increased and was more common in college graduates. Among those trying to lose weight, the most frequently reported strategy was eating fewer calories ( $58 \%$ man, $63 \%$ women) followed by eating less fat $(49 \%, 56 \%)$ and exercising more $(54 \%, 52 \%)$. 
Accuracy in perception of calories and portion sizes in food

It has been reported that perhaps one of the reasons why people fail to lose weight is because they make errors in estimating the calorie content or the portion size of foods (19). In a recent study by Visona and George (20), researchers measured the accuracy of estimation of calories (EI) for foods consumed by 36 overweight females. The researchers reported that participants underestimated $\mathrm{EI}$ by as much as $40 \%$. In an earlier study, Lictman et al (19) reported that participants were unable to accurately estimate portion sizes in reference to food items consumed in a test meal.

\section{Summary}

These studies suggest that nutrition knowledge and knowledge of caloric intake might have an important impact on the selection of foods, and ultimately on the management of body weight. Perhaps, a similar phenomenon occurs in reference to knowledge of the caloric expenditure for different types of PA. However, at this time very little information has been reported on this topic.

\section{Energy Expenditure}

It is possible that cognition also influences participation in PA and therefore ultimately impacts energy expenditure (EE). For example, in a study aimed to determine the effect of increased PA on EI and energy balance in obese women $(\mathrm{N}=6)$, Woo et al. (21), observed that participants decreased their usual PA during the rest of the day after completing an assigned exercise (use of treadmill). Perhaps if individuals believe that they have expended many calories for a specific PA they may believe that they do not 
need to do any other PA during the rest of the day. They may also believe that they should increase their EI. An inaccuracy in perception of calories expended may influence an individual to eat either more or less or may cause them to be more or less active. This would ultimately have an impact on the energy balance of the individual.

Accuracy in perception of EE for PA

Visona and George (20) reported that participants were unable to accurately estimate EE of 60 minutes of moderate intensity PA (walking on a treadmill) and 60 minutes at rest. Accuracy varied from approximately $20 \%$ to $60 \%$. These variations in estimated EE were related to dieting status. Researchers also found that participants were unable to accurately assess caloric content of their EI. Perhaps inaccuracies in estimations of EE and EI play a role in eating and activity behaviors and ultimately, in weight management.

Accuracy in PA recall

Although there is only one known study addressing estimation of EE for PA (20), there are a few studies that have evaluated PA recall. Irwin et al. (22), conducted a study to unveil the determinants of accuracy of estimation of EE from PA measures (using PA records and the Stanford Seven-Day PA Recall) compared with double labeled water. Data was obtained from 24 males who ate a controlled diet designed to maintain body weight. Participants varied in age (27-65), BMI (21-32), percentage body fat (10-43\%), and PA levels. Researchers found that participants who overestimated EE on the PA records had significantly higher BMI and higher percent of body fat compared with men 
who accurately estimated their EE. Further, accuracy of estimated EE increased as PA levels increased.

Tzetzis and colleagues (23) investigated the accuracy of perception of duration and intensity of PA for novice skiers. Seventy-five students, ages 19-21, with no previous ski experience wore heart rate monitors during practice in order to record their exercise intensity. A trained observer recorded their time engaged in the activity. A day later, participants completed a questionnaire providing estimates of perceived duration and intensity during ski practice. Results showed an overestimation of time on task and an underestimation of intensity. These results suggest that individuals may be unable to accurately estimate $\mathrm{EE}$ in reference to time and intensity. It is possible that if individuals are unable to accurately recall time and intensity of a PA, they may also be unable to accurately estimate the caloric expenditure of a specific PA.

\section{Summary}

The lack of available literature about perceived EE makes drawing any conclusion difficult. However, considering the available studies, it is apparent that there could be differences among different groups (i.e., age, gender, education, BMI and PA levels) in their ability to accurately assess EE for different PA.

\section{A review of the theories on the relationship between knowledge and health behavior}

The following explains the role that cognition (knowledge, beliefs and understanding) plays in EI and EE, and ultimately, weight management. 


\section{Social cognitive theory (SCT)}

Also known as Social Learning Theory, SCT defines human behaviors as the result of the interactions of personal factors, behaviors, and the environment (24). SCT contends that behavior is largely regulated through a cognitive process and as such, behavior might be modified if the cognitive processes change. Bandura explains SCT in terms of a dynamic and reciprocal model in which behaviors, personal factors (that include cognition), and environment interact to modify behavior.

\section{Health belief model (HBM)}

Perhaps one of the most widely used models, the HBM proposes that a person will modify a behavior based on the perceived susceptibility of their risk to a disease or condition, the perceived severity of the seriousness of the disease, and the perceived benefits regarding the effectiveness of modifying the behavior (25). In this model, knowledge might play an important role in modifying the individual's perceptions of susceptibility to the risk, severity or perceived benefits.

\section{Trantheoretical model of change (TTM)}

The TTM is an integrative model for behavior change. Key constructs from other theories are integrated in this model. The model describes how people modify a problem behavior or acquire a positive behavior through stages and processes. The stages include: pre-contemplation, contemplation, preparation, action, maintenance, and termination. According to this theory, the intervention for change of behavior will be more effective if it is targeted to the stage of the individual (26). For example, if an overweight individual 
is in the pre-contemplation stage (the stage at which the individual has no intention to take action in the foreseeable future) for weight loss, there are several processes that can be used to move the individual to the next stage of change, which is the contemplation stage (in which the individual intends to take action in the immediate future). One of these processes is consciousness rising, which involves increased awareness, usually though increased knowledge. Theoretically, if an individual became aware of the energy balance equation and understood the concept of calories in food and expended PA, the individual could make changes to assist in effective weight management.

\section{Theory of reasoned action (TRA) and theory of planned behavior (TPB)}

Both TRA and TPB focus on the constructs related to behavior. The theory of reasoned action includes the attitude and the social normative perception that determines behavioral intention, which leads to behavior. The theory of planned behavior is an extension of TRA and includes the perceived control that an individual believes to have over the behavior (27). Overall, both theories focus on cognitive factors (beliefs and knowledge) that determine behavior.

\section{Summary}

All of these models contain constructs that relate to cognition. Therefore, it is believed that knowledge plays a role in influencing lifestyle behaviors that affect body weight. 


\section{REFERENCES}

1. U.S. Department of Health and Human Services. The Surgeon General's call to action to prevent and decrease obesity. Available from:

http:/www.surgeongeneral.gov/topics/obesity/calltoaction/CalltoAction.pdf.

Assessed July 18, 2004.

2. Flegal KM, Carroll MD, Kuczmarski RJ, Johnson CL. Prevalence and trends in obesity among US adults, 1999-2000. J Am Med Assoc. 2002;88:1723-1727.

3. WHO Consultation on Obesity. Obesity: Preventing and managing the global epidemic. Geneva, Switzerland: World Health Organization. World Health Organ Tech Rep Ser. 2000;894:1-253.

4. Lyznicki J, Young D, Riggs J, Davis R. Obesity: Assessment and management in primary care. Am Fam Physician. 2001;63:2185-2196.

5. Goran MI, Treuth MS. Energy expenditure, physical activity, and obesity in children. Pediatr Clin North Am. 2001;48:931-953.

6. Groff JL, Gropper SS. Advanced Nutrition and Human Metabolism. $3^{\text {rd }}$ ed. Wadsworth: Thomson Learning. Belmont, CA. 1999.

7. Goran MI. Variation in total energy expenditure in humans. Obes Res. 1995:3:59-66.

8. National Center for Chronic Disease Prevention and Health Promotion. Nutrition and physical activity: Metabolic equivalent level. Available at:

http://www.cdc.gov/nccdphp/dnpa/physical/measuring/met.htm. Accessed September $28,2003$.

9. Montoye H.J, Kemper HCG, Saris WHM, Washburn RA. Measuring Physical Activity and Energy Expenditure. Human Kinetics Publishers. Champaign, IL. 1996.

10. National Center for Chronic Disease Prevention and Health Promotion. Physical Activity and Health. Surgeon General Report. Available at http://www.cdc.gov/nccdphp/sgr/contents.htm. Accessed November 19, 2003.

11. Barnes PM, Schoenborn CA. Physical activity among adults: United States, 2000. U.S. Department of Health and Human Services. CDC. National Center for Health Statistics. Advanced data from vital and health statistics. Available at: http://www.cdc.gov/nchs/data/ad/ad333.pdf. Accessed October 1, 2003.

12. Wardle K, Parmenter K, Waller J. Nutrition knowledge and food intake, Appetite. 2000;34;269-275. 
13. Larsson I, Lissner L, Wilhelmsen L. The "Green Keyhole' revisited: nutritional knowledge may influence food selection. Eur J Clin Nutrition. 1999;53:776-780.

14. Neuhouser ML, Kristal AR, Patterson RE. Use of food nutrition labels is associated with lower fat intake. $J$ Am Med Assoc. 1999;99:45-50,53.

15. Miller DL, Castellanos VH, Shide DJ, Peters JC, Rolls BJ. Effect of fat-free potato chips with and without nutrition labels on fat and energy intakes. Am J Clin Nutr. 1998;8:282-90.

16. Brewer JL, Blake AJ, Rankin SA, Douglas LW. Theory of reasoned action predicts milk consumption in women. $J$ Am Med Assoc. 1999;99:39-44.

17. Kruger J, Galuska DA, Serdula MK, Jones DA. Attempting to lose weight. Specific practices among U.S. adults. Am J Prev Med. 2004; 26: 402-406.

18. Mangweth B, Hudson JI, Pope HG, Oberleit S, De Col C, Kinzl J. Knowledge of calories and its effect on eating behavior in overweight, normal weight, and underweight individuals. Eat Weight Disord. 1999;4:165-168.

19. Litchman SW, Pisarska K, Berman ER, Pestone M, Dowling H, Offenbacher E, Weiserl H, Heshka S, Matthews DE, Heymsfield SB. Discrepancy between selfreported and actual caloric intake and exercise in obese subjects. $N$ Engl J Med. 1992;327:1893-1898.

20. Visona C, George VA. The impact of dieting status and restraint on post-exercise energy intake in overweight females. Obes Res. 2002;10:1251-1258.

21. Woo R, Garrow JS, Pi-Sunyer FX. Effects on spontaneous calorie intake in obesity. Am J of Clin Nutr. 1982;36:470-477.

22. Irwin ML, Ainsworth BE, Conway JM. Estimation of energy expenditure from physical activity measures: Determinants of accuracy. Obes Res. 2001; 9:517-525.

23. Tzetzis G, Avgerinos A, Vernadakis N, Kioumrtzoglou E. Differences in selfreported perceived and objective measures of duration and intensity of physical activity for adults in skiing. Eur J Epidemiol. 2001;17:217-222.

24. Bandura A. Social Foundations of Thought and Action: A Social Cognitive Theory. Englewood Cliffs: N.J.Prentice Hall Publishers. 1986.

25. Strecher VJ, Rosenstock IM. The health belief model. In: Glanz K, Lewis FM, Rimer BK. Health Behavior and Health Education. $2^{\text {nd }}$ ed. Jossey-Bass Inc., Publishers. 1997; 41-48. 
26. Prochaska JO, Redding CA, Evers KE. Transtheoretical model and stages of change. In: Glanz K, Lewis FM, Rimer BK. Health Behavior and Health Education. $2^{\text {nd }}$ ed. Jossey-Bass Inc., Publishers. San Francisco, CA. 1997;60-84.

27. Montano DE, Kasprzyk D, Taplin SH. The theory of reasoned action and the theory of planned behavior in health behavior and health education. In: Glanz K, Lewis FM, Rimer BK. Health Behavior and Health Education. $2^{\text {nd }}$ ed. Jossey-Bass Inc.,Publishers. San Francisco, CA. 1997;85-112. 


\section{CHAPTER III}

\section{MANUSCRIPT}

\section{PERCEIVED CALORIES FOR DAILY PHYSICAL ACTIVITIES IN MEN AND WOMEN}

\section{INTRODUCTION}

Overweight and obesity have reached epidemic proportions in the United States. Data from the 1999-2000 National Health and Nutrition Examination Survey (NHANES 1999-2000) shows that $64.5 \%$ of U.S. adults are overweight or obese (1). This is a dramatic increase when compared with 1976-1980 estimates, in which $32 \%$ of adults were reported overweight and 15\% obese (2). This increase in overweight and obesity is particularly evident in minority populations. It has been reported (1) that Hispanic males have a slightly higher prevalence of obesity (29\%) than non-Hispanic Blacks (28\%) or non-Hispanic whites (27\%). In females, non-Hispanic black women (50\%) and MexicanAmerican women (40\%) have a greater prevalence of obesity than non-Hispanic white women $(30 \%)(1)$.

Overweight and obesity have become one of the most pressing health problems in the United States (3). Inadequate diet and physical inactivity account for approximately 400,000 deaths per year (4). Is has been well established that excess body weight is an important risk factor for type 2 diabetes, hypertension, stroke, heart disease, gallbladder disease, sleep apnea, certain cancers (i.e., endometrial, breast, prostate, and colon), ostereo-arthritis, dislipidemia, and reproductive complications, as well as certain psychological disorders (depression, eating disorders, distorted body image, and low selfesteem) (5-9). According to the World Health Organization, overweight is defined as a 
body mass index $(\mathrm{BMI}) \geq 25$, obesity as a $\mathrm{BMI} \geq 30$, and extreme obesity a $\mathrm{BMI} \geq 40$ (10). In the year 2000, it was estimated that direct and indirect costs associated with overweight and obesity amounted to approximately $\$ 117,000$ billion dollars (3). It has been reported that health care costs increase $36 \%$ for individuals with a BMI $\geq 30$ and $20 \%$ for those with a BMI of $\geq 25(11)$.

Overweight and obesity are the result of the positive energy balance in relation to energy intake (EI) and energy expenditure (EE), over an extended period of time $(6,12)$. Psychological, biological and cognitive factors contribute to the EI and EE of an individual (12). Lifestyle behaviors that influence diet and participation in PA may be influenced by cognition, i.e., knowledge, beliefs, and understanding about EI and EE (1316). In an attempt to have a healthy body weight, some individuals use information about calories in EI and EE to create a plan to help manage their weight. It has been reported that eating fewer calories is one of the most commonly used strategies for weight loss (17). Other studies have found that some individuals might use the information about calories to select specific food items (18-19). Therefore, perception of calories plays an important role in the EI of some individuals.

It is also possible that cognition influences participation in PA and ultimately EE. For example, if individuals believe they have expended many calories through a particular PA, they may think that they do not need to do any other PA during the rest of the day, or they may believe that they should increase their EI. In a study by Woo et al. (20), designed to determine the effect of increased PA on EI and energy balance in obese females, researchers found that the participants decreased their usual PA during the rest of the day after completing an assigned exercise. In a recent study, Visona and George 
(21) reported that participants were unable to accurately estimate EE in reference to 60 minutes of moderate intensity walking on a treadmill and 60 minutes at rest. Accuracy varied from approximately $20 \%$ to $60 \%$. These variations in estimated EE were related to dieting status.

Very little information is available in the literature on the perception of caloric expenditure for different PA. Information on perception of calories expended during PA of daily life could provide some insight into the relationship between cognition and PA and, ultimately, how perceived EE for PA might influence body weight.

\section{RESEARCH METHODS AND PROCEDURES}

\section{Study design and recruitment}

This was a descriptive study aimed at assessing the knowledge of males and females, both normal and overweight individuals of diverse ethnicity, education and activity levels on their perception of $\mathrm{EE}$ for various $\mathrm{PA}$.

Eight hundred participants were randomly recruited from ten sites of the Department of Motor Vehicles in Miami-Dade County of Florida. Participation was on a volunteer basis and all the participants received a letter of informed consent (See Appendix A). The letter explained that by completing the survey, subjects were giving their consent to participate in the study. The Institutional Review Board of Florida International University approved the protocol. Participants were eligible if they were between 21-64 years of age, ambulatory and without disabilities. Data collection took place from September 2003 to January 2004. 


\section{Assessment tools}

A 19-item questionnaire (The Energy Expenditure Questionnaire) was developed to assess perception of EE for various PA (See Appendix B). This questionnaire was interviewer administered and contained ten questions regarding perceived caloric value for different intensity PA (sedentary, moderate and vigorous). In addition, it included four demographic questions assessing age, gender, ethnicity and education level, two anthropometrics questions (weight and height) and the Godin Leisure Time Questionnaire (22). Participants also answered one question regarding the source of information used to determine the caloric value for the different PA. Content and construct validity of the questionnaire was determined by experts in the field. Reliability of the questionnaire was tested using a pilot study among a convenient sample of 50 individuals. Subjects completed the assessment instrument twice with a one-week interval. The paired sample correlations for the ten PA assessed was $r=0.76$ (range was 0.57-0.79) (See Appendix C).

\section{Perceived caloric value for different PA}

The ten questions assessing perception of PA reflected activities from the Bouchard (23) three-day PA record and represented light, moderate, and strenuous $\mathrm{PA} /$ exercise. The approximate energy cost of each type of $\mathrm{PA}$ in $\mathrm{kcal} / \mathrm{kg} / 15$ min intervals, multiplied times 4 was used to compute the EE per kilogram of body weight for 60 minutes of the specific type of PA. Finally, the result of the equation was multiplied by the individual participant's self-reported weight in kilograms. 


\section{The Godin Leisure Time Questionnaire}

The Godin leisure time exercise questionnaire assesses leisure time physical activity (LTPA) and consists of three questions based on 7-day recall. This questionnaire has been reported to be a valid and reliable measurement of different types of exercises during leisure time, including strenuous, moderate and mild exercise (22). A total LTPA score was calculated for each participant by multiplying frequency (times/week) by each of the PA levels (i.e. strenuous $=9$, moderate $=5$, and light $=3$ ). The sum of the individual scores provided the final LTPA score.

\section{BMI}

Self reported weight and height has been reported to be an acceptable method to determine BMI (24). Based on guidelines from the World Health Organization (10), participants were classified as follows: normal weight (BMI $\leq 24.9$ ), overweight (BMI $\geq$ $25)$, and obese (BMI $\geq 30$ ).

\section{Source of information on calories expended for PA}

After participants completed the question regarding the perceived EE for PA, they were asked to report the source of information they used to determine the caloric value for the different PA. Participants could select from five fixed alternative responses or provide an alternative source.

\section{Statistical analysis}

Statistical analysis was performed using the SPSS software version 12.0 (SPSS Inc. Chicago, IL, 2003). Descriptive statistics were used to determine the ranges of 
estimation of calories. Frequencies were produced to describe gender, age, BMI, education, and LTPA levels for participants. Cross tabulations were used to analyze the percentage of participants estimating the caloric value for the different PA within different accuracy ranges (underestimating $>50 \%$, under or overestimating within $50 \%$, or overestimating $>50 \%$ ) of the actual value. Chi-square tests were used to test the statistical significance of the relationships between age, gender, education and PA levels, as well as BMI and the accuracy of estimation of the number of calories for different physical activities. A value of $\mathrm{p}<0.05$ was considered significant.

Power analysis for chi-square tests of accuracy range by gender with 2 degrees of freedom yielded $97 \%$ power to detect a medium effect size of $0.15(\mathrm{p}<0.05)$. Chi-square tests of accuracy range by education (PA, BMI) with 4 degrees of freedom achieved $94 \%$ power, and by age, with 6 degrees of freedom, $91 \%$ power was achieved to detect a medium size effect of $0.15(p<0.05)$.

\section{RESULTS}

Eight hundred people completed the Energy Expenditure Questionnaire. Three individuals were excluded from the study because of missing or erroneous data. In total, 797 individuals, (389) females, and (408) males, participated in the study. Two participants did not provide information on their education level.

Descriptive characteristics of the participants in reference to education level and gender, ethnicity, age, LTPA and BMI are shown in Table 1. The majority of the participants were Hispanics (78\%). The largest percentage of participants were between 
the 21-30 years of age (38\%). Only $15 \%$ were between the ages of $51-64$ years of age. The majority of the participants had attended college (63\%). Forty percent of the participants reported that they were college graduates or had done graduate studies. Almost $60 \%$ of the participants were categorized as inactive and $12 \%$ as active. In addition, based on reported height and weight, $38 \%$ of the participants had a BMI placing them in the category of overweight and $22 \%$ had a BMI categorizing them as obese.

Table 2 shows the range of estimated and actual calories for the different PA. There was an extremely wide range for estimated calories for all activities. The range for sedentary activities was from zero to 10,000 , moderate activities from zero to 60,000 , and vigorous activities from zero to 20,000 calories. Table 2 also illustrates the percentage of participants whose estimation was under, within or over $50 \%$ the actual calculated caloric value for different PA. Overall, only $30 \%$ of the participants were able to accurately estimate EE for the 10 activities surveyed. Accuracy was defined as having an estimate within $50 \%$ of the calculated EE (over or under) for the specific activity. The highest percentage of underestimation (67\%) was for light to moderate activities (sitting, standing, getting dressed). This is in contrast with the greatest percentage of overestimation which was in moderate sport or leisure activity (25\%).

Figure 1 illustrates the accuracy in estimation by activity level. Approximately $45 \%$ of participants underestimated the number of calories for all intensities of PA within the range $-50 \%$ and $-100 \%$. Sedentary and moderate intensity PA were underestimated by more than $100 \%$ by $16 \%$ of the participants. This is in contrast with $<1 \%$ underestimating by more than $100 \%$ for vigorous PA. 
Level of education proved to be an important determinant for accuracy in estimation. As shown in Figure 2, individuals with more education were significantly $(p<0.005)$ more accurate in their estimation of EE than the other education groups. The primary difference among the three education groups was between high school and college graduates, with the exception of the estimation regarding standing, in which case there was a lower percentage in accuracy among the group that had some college education. It was hypothesized that there would be differences between age and accuracy of perceived $\mathrm{EE}$ for activities. We found that younger individuals (21-30 years of age) were more accurate in their perception of $\mathrm{EE}(\mathrm{p}<0.05)$ compared with older individuals for moderate and vigorous physical activities.

\section{DISCUSSION}

The results of this study showed that out of the 797 participants surveyed, only $30 \%$ of the participants were able to accurately estimate EE (within $50 \%$ of the calculated EE) for ten different PA. Although there are no reported studies specifically addressing the ability of different populations to assess EE for various physical activities, a study by Visona and George (21) on post-exercise EI reported on their participants' ability to estimate EE at rest and after moderate intensity PA. In that study, on the average, participants underestimated $\mathrm{EE}$ at rest by approximately $50 \%$. Their estimation for $\mathrm{EE}$ during 60 minutes of moderate intensity PA was overestimated by $20 \%$ in non-dieters and underestimated by $20 \%$ for the dieters.

In this study, the most significant variable influencing accuracy in perception was education. College graduates were more accurate in their estimation of the number of 
calories for the PA surveyed than less educated participants. Perhaps, individuals with more education have more exposure to information about the caloric value of $\mathrm{EE}$ associated with activity in courses of higher learning.

Age was also a dominant factor in accuracy of perception. We found that younger adults (21-30 years of age) were more accurate in their perception of EE for moderate and vigorous PA than older adults. Our results could relate to the fact that younger adults have been reported to participate in moderate and vigorous PA more frequently than older adults (25). In addition, younger adults may also be exposed to more information about PA based on their concerns about appearance and body weight.

In our study, we did not find differences between the genders and level of PA in reference to accuracy of perceived EE for activities. It has been reported that women diet more frequently than men (17) and that they have greater nutrition knowledge and apply their knowledge by reading food labels to make food choices (14-15). This suggests that women might be more familiar with the concept of a calorie and the caloric content of certain foods. It was hypothesized that such knowledge might be applied to the understanding of the calories expended doing various PA. Some studies have shown that men are more physically active than women (25-26). Perhaps greater participation in physical activity increases exposure to information about calories used for different types of PA.

Surprisingly, there was no significant difference in perception of accuracy among the different weight groups. It was hypothesized that the normal weight group would be more accurate in their assessment because they might be using knowledge of energy expenditure for activities to determine their diet and exercise program to maintain their 
weight. On the other hand, perhaps there was no difference between the weight groups because the overweight individual that is trying to reduce their body weight might be making a greater effort to learn more about calories both in food intake and calories used during PA. Reports indicate that overweight individuals diet more frequently (17) and that they use knowledge of calories to determine their food choices (18). Therefore, theoretically both normal and overweight individuals might have some level of knowledge about the caloric value of EE for PA. However, $84 \%$ of the participants reported that they had guessed in response to the questions on their source of information for the different PA. This method was confirmed by the extremely wide range of estimated calories for sixty minutes of activity for all activity levels. For example, for sedentary activities the range was from zero to ten thousand, for moderate from zero to sixty thousand and for vigorous from zero to twenty thousand.

Since approximately $70 \%$ of the people surveyed were unable to accurately estimate EE for PA this indicates that education is needed to inform people about the actual caloric value for $\mathrm{EE}$ in different types of PA. A number of educational and health theories, such as the Social Cognitive Theory (28), the Health Belief Model (29), and the Transtheoretical Model of Change (30), suggest that cognition does play a role in behavior. Theoretically, if we could teach people about calories for $\mathrm{EE}$ as well as for $\mathrm{EI}$ this could assist them in managing their weight.

These results suggest that efforts should be made to help the public understand the actual calories that are expended for sedentary, moderate, and vigorous PA based on duration of the activity and body weight. As confirmed by the recently announced FDA strategy, efforts need to be made to educate the public about the concept of "energy 
balance" and the importance of the calories needed to maintain body functions and do PA (31). Such accounting may assist individuals in making the right food and activity choices that will allow them to manage their weight more effectively. Dietitians have a key role to play in educating the public regarding energy balance and calorie counting in food as well as daily PA.

Recently, the United States Department of Health and Human Services (HHS) unveiled a Food and Drug Administration strategy to aid in the campaign to reduce overweight and obesity (21). The focus is a "calories count" approach. Recommendations are centered on the importance of educating consumers on the fact that weight control is primarily a function of calorie balance. The FDA recommendations include: revisions of food labels to highlight the role calories play in the maintenance of an adequate diet, authorizations of health claims on foods that meet the definition of "low or reduced calories", displays of nutrition information for consumers at restaurant establishments, and dietary guidance statements by manufactures to educate consumers about the importance of a balanced $\mathrm{EI}$ and $\mathrm{EE}$. The results of this study indicate that this new campaign should also focus on providing information on the caloric value for different types of physical activity.

Our study had some limitations. Participants were recruited randomly from 10 different offices of the Miami-Dade County, Florida Motor Vehicle Department. Therefore, the sample was limited to individuals who were renewing their license in person, rather than on-line or by mail. The population evaluated was predominantly Hispanic (78\%). However, since the prevalence of overweight and obesity in the Hispanic population is high (over one third of Hispanic American adults can be 
categorized as being overweight or obese (U.S. Department of Health and Human Services, 2002) (32) and the Hispanic population is the second largest minority group in the United States (12\%) (33), it seems relevant to evaluate their knowledge about a weight related issue. Finally, BMI was based on self reported height and weight. Although this could be considered biased, the self reporting of height and weight are considered to be an acceptable method of assessment (34).

\section{CONCLUSION AND APLICATION}

In conclusion, this is the first study ever reported on perceived EE (calories) for a variety of daily PA (sedentary, moderate, and vigorous). Further, this study was the first to explore BMI, LTPA, gender, age, and education in reference to accuracy of perceived EE for these types of activities. Future studies should be designed to determine how to teach people about the caloric value of various daily PA. Such intervention studies could also evaluate the impact of knowledge of calories for different PA on the incorporation of

more PA into an individual's lifestyle. A number of studies (35-36) have already reported that information from a pedometer (i.e., number of steps, caloric expenditure) has served to increase the number of steps an individual may take during ad day. Finally, more efforts need to be made through the school system to incorporate information about calories and EE. This is particularly relevant for children who have the potential to integrate this information into the development of an active adult lifestyle. 


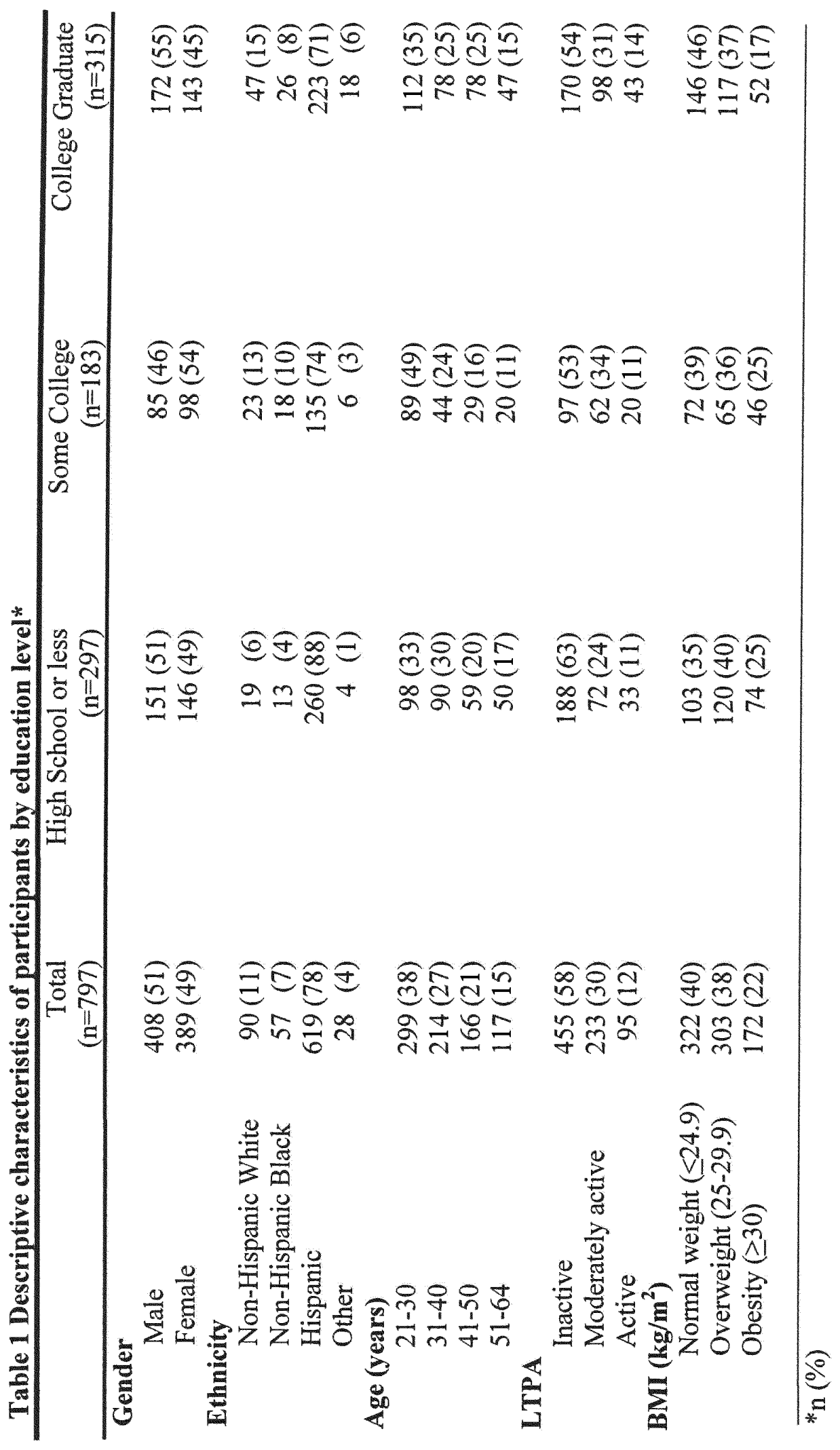




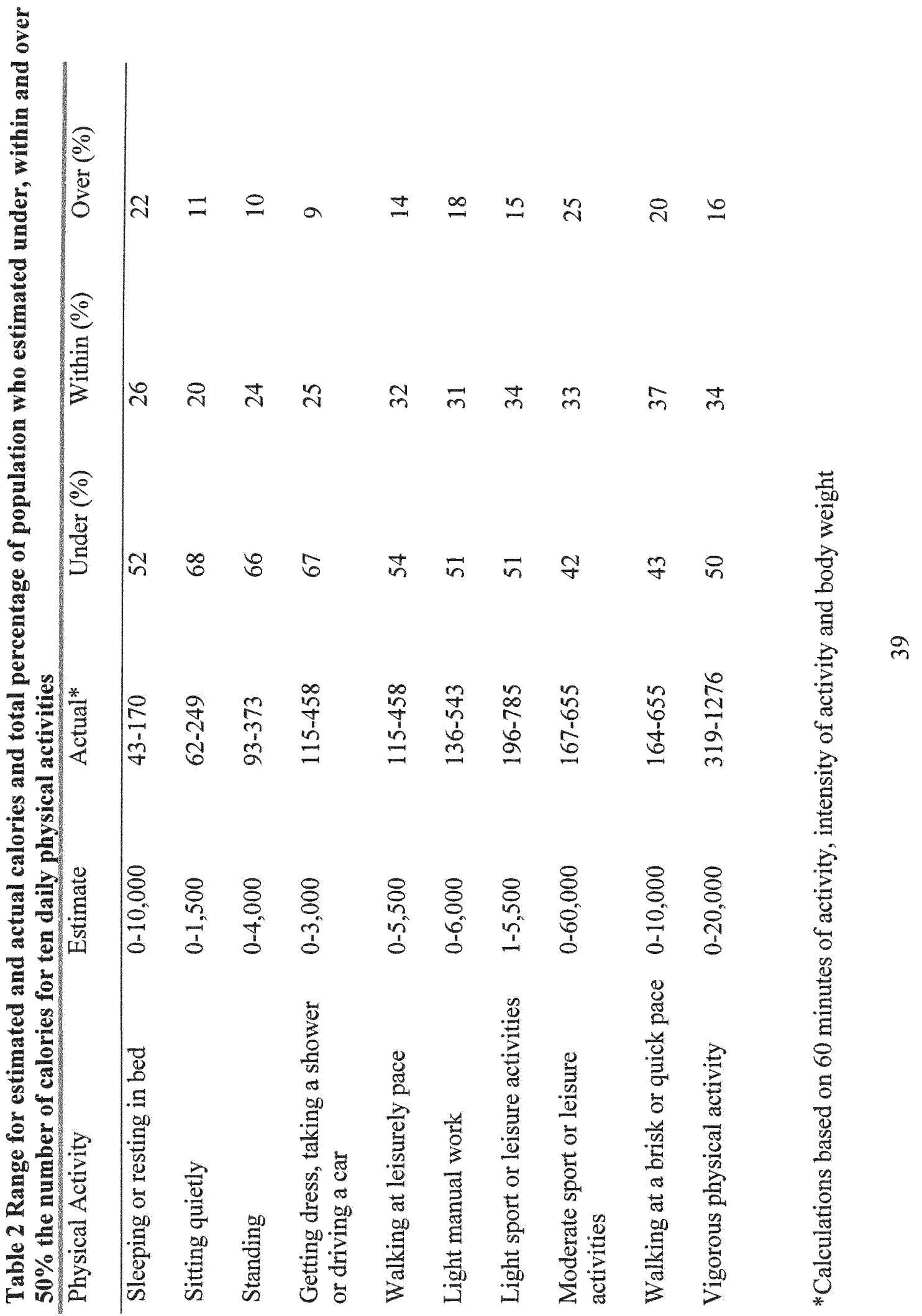




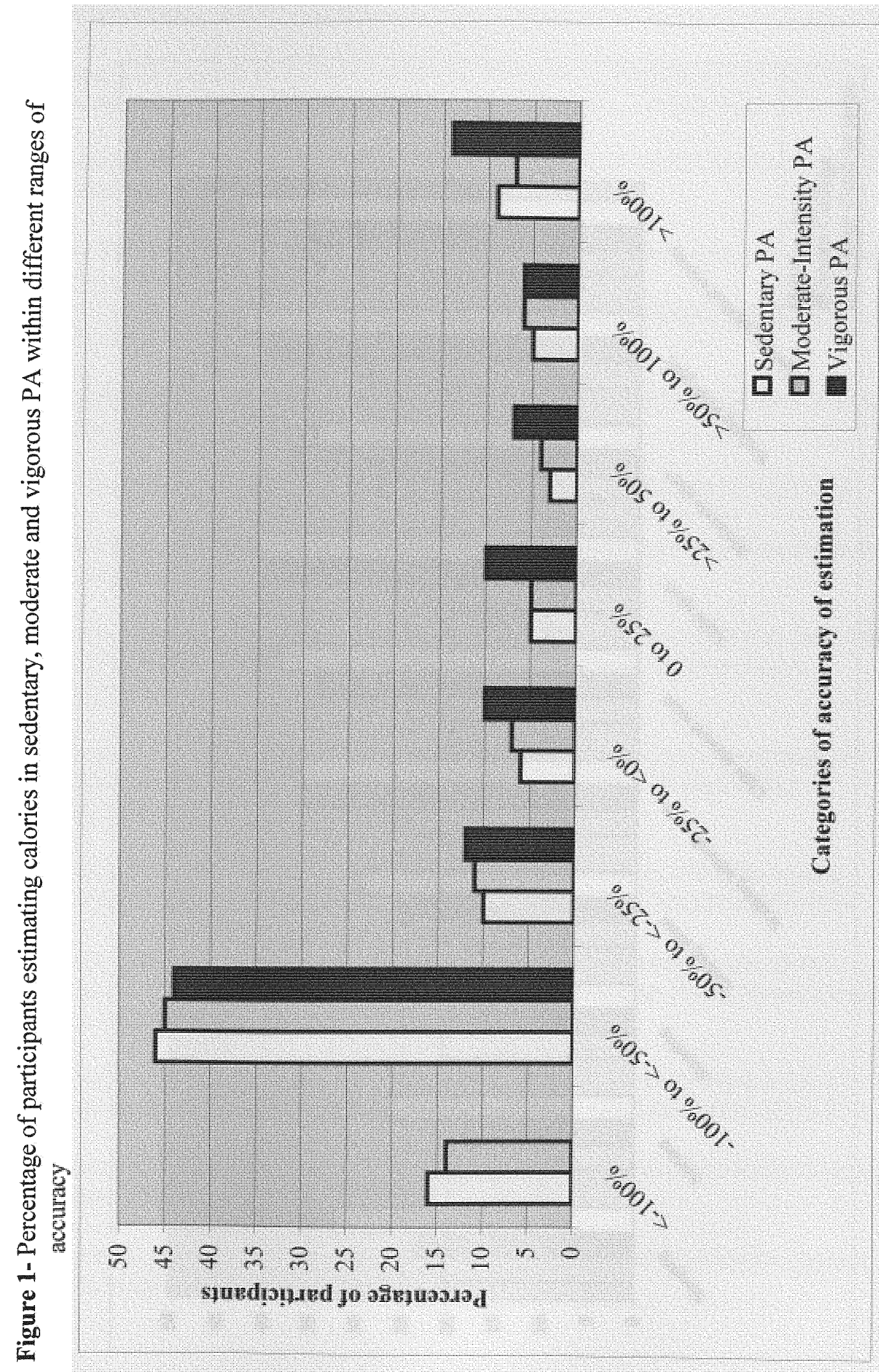




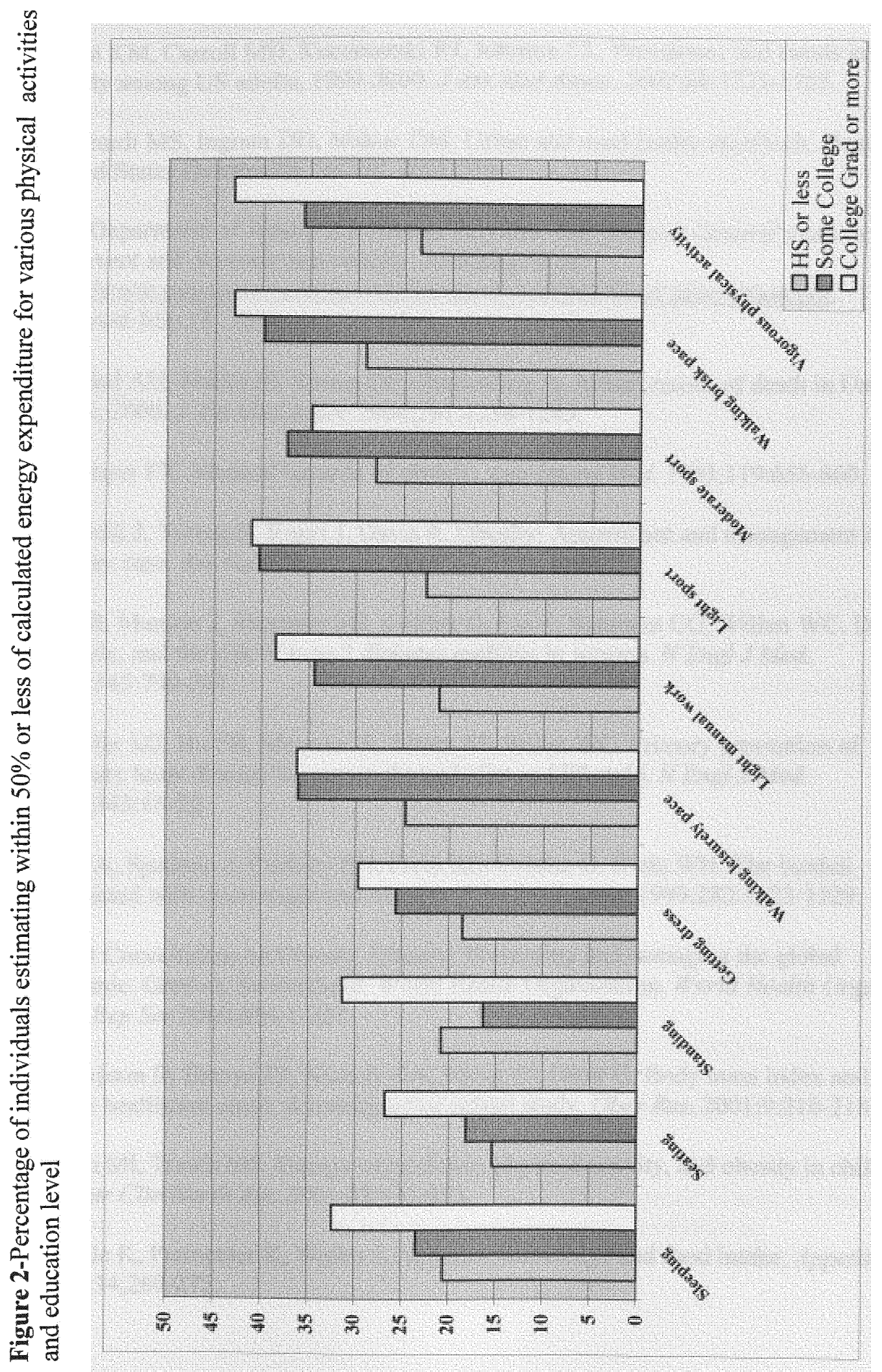




\section{REFERENCES}

1. Flegal KM, Carroll MD, Kuczmarski RJ, Johnson CL. Prevalence and trends in obesity among US adults, 1999-2000. J Am Med Assoc. 2002;88:1723-1727.

2. Eberhardt MS, Ingram DD, Makuc DM. Urban and rural health chartbook. Health United States.Hyatttsville, NCHS. $2001 ; 256$.

3. U.S. Department of Health and Human Services. The Surgeon General's call to action to prevent and decrease and obesity. Available from: http://www.surgeongeneral.gov/topics/obesity/calltoaction/CalltoAction.pdf. Assessed July 18, 2004.

4. Mokdad AH, Marks JS, Stroup DF, Gerberding JL Actual causes of death in United States, 2000. J Am Med Assoc. 2004;291:1238-1245.

5. Pi-Sunyer FX .Medical hazards of obesity. Ann Intern Med. 1993;119:655-660.

6. Lyznicki J, Young D, Riggs J, Davis R. Obesity: Assessment and management in primary care. Am Fam Physician. 2001;63:2185-2196.

7. Hu FB, Manson J, Stampfer MJ, Colditz G, Liu S, Solomon CG, Willett WC. Diet, lifestyle, and the risk of type-2 diabetes mellitus in women. $N$ Engl J Med. 2001;345:790-797.

8. Sampfer MJ, Hu FB, Manson JE, Rimm EB, Willet WC. Primary prevention of coronary heart disease in women through diet and lifestyle. $N$ Engl $J$ Med. 2000;343:16-22.

9. Must A, Spadano J, Coakley EH, Field AE, Colditz G, Dietz WH. The burden associated with overweight and obesity. J Am Med Assoc. 1999;282:1523-1529.

10. WHO Consultation on Obesity. Obesity: Preventing and managing the global epidemic. Geneva, Switzerland: World Health Organization. World Health Organ Tech Rep Ser.2000;894:1-253.

11. Thompson D, Brown JB, Nichols GA, Elmer PJ, Oster G. Body mass index and future healthcare costs: A retrospective cohort study. Obes Res. 2001;9:210-218.

12. Goran MI, Treuth MS. Energy expenditure, physical activity, and obesity in children. Pediatr Clin North Am. 2001;48:931-953.

13. Wardle K, Parmenter K, Waller J. Nutrition knowledge and food intake, Appetite. 2000;34;269-275. 
14. Neuhouser ML, Kristal AR, Patterson RE. Use of food nutrition labels is associated with lower fat intake. $J$ Am Med Assoc. 1999;99:45-50,53.

15. Larsson I, Lissner L, Wilhelmsen L. The "Green Keyhole" revisited: nutritional knowledge may influence food selection. Eur J Clin Nutrition.1999;53:776-780.

16. Miller DL, Castellanos VH, Shide DJ, Peters JC, Rolls BJ. Effect of fat-free potato chips with and without nutrition labels on fat and energy intakes. Am J Clin Nutr. 1998;8:282-90.

17. Kruger J, Galuska DA, Serdula MK, Jones DA. Attempting to lose weight. Specific practices among U.S. adults. Am J Prev Med..2004;26:402-406.

18. Mangweth B, Hudson JI, Pope HG, Oberleit S, De Col C, Kinzl J. Knowledge of calories and its effect on eating behavior in overweight, normal weight, and underweight individuals. Eat Weight Disord. 1999;4:165-168.

19. Brewer JL, Blake AJ, Rankin SA, Douglas LW. Theory of reasoned action predicts milk consumption in women. $J$ Am Med Assoc. 1999;99:39-4.

20. Woo R, Garrow JS, Pi-Sunyer FX. Effects on spontaneous calorie intake in obesity. Am J Clin Nutr. 1982:36,470-77.

21. Visona $\mathrm{C}$, George VA. The impact of dieting status and restraint on post-exercise energy intake in overweight females. Obes Res.2002;10:1251-1258.

22. Godin G, Shephard RJ. A simple method to assess exercise behavior in the community. Can. J. Appl. Spt. Sci.1985;10:141-146.

23. Bouchard C, Tremblay A, Leblanc C, Lortie G, Savard R, Theriault G. A method to assess energy expenditure in children and adults. Am J Clin Nutr.1983; 37:461-467.

24. Stunkard AF, Albaum JM. The accuracy of self-reported weights. Am J Clin Nutr. 1982;34:1593-1599.

25. National Center for Chronic Disease Prevention and Health Promotion. Physical Activity and Health. Surgeon General Report. Available at http://www.cdc.gov/nccdphp/sgr/contents.htm. Accessed February 19, 2004.

26. Barnes PM, Schoenborn CA. Physical activity among adults: United States, 2000. U.S. Department of Health and Human Services. CDC. National Center for Health Statistics. Advanced data from vital and health statistics. Available at: http://www.cdc.gov/nchs/data/ad/ad333.pdf. Accessed February 23, 2004. 
27. Irwin ML, Ainsworth BE, Conway JM. Estimation of energy expenditure from physical activity measures: Determinants of accuracy. Obes Res.2001; 9:517-525.

28. Bandura A. Social foundations of thought and action: A social cognitive theory. Englewood Cliffs: N.J.Prentice Hall Publishers. 1986.

29. Strecher VJ, Rosenstock IM. The health believe model. In: Glanz K, Lewis FM, Rimer BK. Health Behavior and Health Education. $2^{\text {nd }}$ ed. Jossey-Bass Inc., Publishers.1997;41-48.

30. Prochaska JO, Redding CA, Evers KE. Transtheoretical Model and Stages of Change. In: Glanz K, Lewis FM, Rimer BK. Health Behavior and Health Education. $2^{\text {nd }}$ ed. Jossey-Bass Inc., Publishers.1997;60-84.

31. FDA Obesity Workgroup. HHS Tackles Obesity. FDA Consum. Available at: http://www.fda.goc/fdac/features/2004/304. Accessed June 6, 2004.

32. U. S. Department of Health and Human Services, Centers for Disease Control and Prevention. National Center for Health Statistics. (2002) Healthy Weight, Overweight and Obesity Among U.S. Adults. Available from Centers for Disease control website, http://www.cdc.gov/nchs/data/nhanes/databriefs/adultweight.pdf

33. U.S. Census Bureau. Available at: http://factfinder.census.gov. Accessed July 25, 2004.

34. Croteau KA. A preliminary study on the impact of a pedometer-based intervention on daily steps. Am J Health Promot. 2004;8(3):217-220.

35. Swartz AM, Strath SJ, Bassett DR, Moore JB, Redwine BA, Groer M, Thompson DL. Increasing daily walking improves glucose tolerance in overweight women. Prev Med. 2003;37:356-362.

36. National Center for Chronic Disease Prevention and Health Promotion. Physical Activity and Health. Surgeon General Report. Available at http://www.cdc.gov/nccdphp/sgr/contents.htm. Accessed November 19, 2003. 
APPENDIX A-Consent form 


\section{CONSENT FORM}

\section{PERCEIVED ENERGY EXPENDITURE FOR PHYSICAL ACTIVITY IN MALE AND FEMALE ADULTS}

My name is Su Nui Escobar. I am a graduate student at Florida International University. I am working with Dr. Valerie George in a study to learn more about physical activity. Our study includes a short questionnaire that will take about 10 minutes to complete.

The purpose of this study is to enable researchers to better understand the cognitive factors associated with physical activity.

By completing this questionnaire you are indicating your consent to take part in our study. You will also be indicating that you understand that your responses will be kept strictly confidential by encoding the questionnaire using a number instead of your name.

You might keep this form just in case you want to contact someone about the study. If you have questions about the study you can contact Su-Nui Escobar at escobarsuny@aol.com or (305) 273-0897 or if you have questions or concerns about being in the study you might contact the Chairperson of the Institutional Review Board at Florida International University, Dr. Gerstman at 305-348-3115. 
APPENDIX B - Energy Expenditure Questionnaire 
Please complete all the questions:

\section{APPENDIX B}

- How old are you?

What is your gender?

$\square$ Female $\quad \square$ Male

- What is the highest grade or year of school you completed?

Never attended school or only attended kindergarten

$\square \quad$ Grades 1 through 8 (Elementary)

Grades 9 through 11 (Some high school)

- Grade 12 or GED (High school graduate)

․ College 1 year to 3 years (Some college or technical school)

․ College 4 years or more (College graduate)

[ Graduate studies

- Which one of the groups would you say best represents your race?

$\square$ White, non-Hispanic

$\square$ American Indian, Alaska Native

$\square$ Asian $\square$ Black, non-Hispanic $\square$ Hispanic

$\square$ Native Hawaiian or Other Pacific Islander

$\square$ Other: (specify)

How many calories do you think you use/burn/expend when you do the following activities for 60 minutes?

1. Sleep or rest in bed

2. Sit quiet

3. Stand

(i.e. read, write, listen to radio or TV or work on computer)

(i.e. wait in line, cook, comb hair)

4. Get dress, take a shower, drive a car or take a walk in the mall

5. Walk at a leisurely pace

(i.e. shopping, strolling)

6. Do light manual work

(i.e. housework, clean the car, gardening, carpentry)

7. Do light sport or leisure activities

(i.e. table tennis, golf, volleyball, easy bicycling, easy swimming, dance)

8. Do moderate sport or leisure activities

(i.e. tennis, jog, swim)

9. Walk at a brisk or quick pace

10. Do vigorous physical activity (something that makes you sweat)

(i.e. run, dance, play basketball, heavy construction work) 
1. Considering a 7-day period (a week), how many times on the average do you do the following kinds of exercise for more than 15 minutes during your free time?

\section{Times per week}

\section{a. STRENEOUS EXERCISE}

(Heart beats rapidly)

(i.e. running, jogging, hockey, football, soccer, squash, basketball, cross country, skiing, judo, roller skating, vigorous swimming, vigorous long distance bicycling)

b. MODERATE EXERCISE (not exhausting)

(i.e. fast walking, baseball, tennis, easy bicycling, volleyball, badminton, easy swimming, alpine skiing, popular and folk dancing)

\section{c. MILD EXERCISE}

(Minimal effort)

(i.e yoga, archery, fishing from river bank, bowling, horseshoes, golf snow- mobiling, easy walking)

2. Considering a 7-day period (a week), during your leisure-time, how often do you engage in any regular activity long enough to work up a sweat (heart beats rapidly)?

Often

Sometimes

Never/Rarely

- What is your current weight without shoes? Pounds

- What is your height without shoes? Feet inches 
How did you estimate the number of calories for each physical activity?

$\square$ I guessed

$\square$ From information in a book or magazine

$\square$ From information on the Internet

$\square$ From information at the gym

$\square$ Form information provided by personal trainer

$\square$ Other 
APPENDIX C-Pilot Study 


\section{RELIABILITY OF THE ENERGY EXPENDITURE QUESTIONNAIRE}

\section{Study design and recruitment}

Reliability of the Energy Expenditure Questionnaire was assessed with a pilot study. Fifty participants were recruited randomly from a convenient sample. Participation was on a volunteer basis and all the participants received a modified letter of informed consent (See Appendix A). The letter explained to the participants that by completing the survey, they gave their consent to participate in the study. The Institutional Review Board of Florida International University approved the protocol. Data collection took place during summer 2003. Participants completed the assessment instrument two times with a one-week interval.

\section{Statistical analysis}

Statistical analysis was performed using the SPSS software version 12.0 (SPSS Inc. Chicago, IL 2003). Cross tabulations were used to analyze the percentage of participants that were in the different groups in relation to gender, age, BMI, and education level of participants. Paired sample correlations were generated to test reliability between the first and second assessments.

\section{Results and Conclusion}

Fifty individuals participated in the pilot study and they varied in gender, age, BMI, and education. The correlation between the fist and second assessments for all these variables was 1.0. Table one shows the correlation values for the different PA between the two assessments. The correlations ranged from (0.57-0.79). Therefore, the Energy 
Expenditure Questionnaire was proven to be a reliable method to determine the estimation of calories for different PA. Reliability of the Godin leisure time exercise questionnaire has been previously tested (22). 
Table 4-Correlation values for the ten different PA between the two assessments with one-week interval

\section{Physical Activity}

Physical Activity

Sleeping or rest in bed

Sitting quiet

Standing

Getting dress, take a shower or drive a car

Walking at leisurely pace

Light manual work

Light sport or leisure activities

Moderate sport or leisure activities

Walking at a brisk or quick pace

Vigorous physical activity
Correlation

.76

.79

.77

.68

.57

.69

.72

.72

.69

.67

.98 